\section{Arriba: effects of an educational intervention on prescribing behaviour in prevention of CVD in general practice}

\author{
Heidemarie Keller', Tanja Krones, ${ }^{1,2}$, Annette Becker', \\ Oliver Hirsch', Andreas C Sönnichsen ${ }^{3}$, Uwe Popert ${ }^{4}$, \\ Petra Kaufmann-Kolle ${ }^{5}$, Justine Rochon ${ }^{6}$, Karl Wegscheider ${ }^{7}$, \\ Erika Baum' and Norbert Donner-Banzhoff'
}

Cardiology

19(3) 322-329

(C) The European Society of

Cardiology 2011

Reprints and permissions:

sagepub.co.uk/journalsPermissions.nav DOI: 10.1 | $77 / 174|8267| 1404502$ ejpc.sagepub.com

(SAGE

\begin{abstract}
Background: Evidence on the effectiveness of educational interventions on prescribing behaviour modification in prevention of cardiovascular disease is still insufficient. We evaluated the effects of a brief educational intervention on prescription of hydroxymethylglutaryl-CoA reductase inhibitors (statins), inhibitors of platelet aggregation (IPA), and antihypertensive agents $(\mathrm{AH})$.

Design: Cluster randomised controlled trial with continuous medical education (CME) groups of general practitioners (GPs).

Methods: Prescription of statins, IPA, and AH were verified prior to study start (BL), immediately after index consultation (IC), and at follow-up after 6 months (FU). Prescription in patients at high risk (>15\% risk of a cardiovascular event in 10 years, based on the Framingham equation) and no prescription in low-risk patients $(\leq 15 \%)$ were considered appropriate.

Results: An intervention effect on prescribing could only be found for IPA. Generally, changes in prescription over time were all directed towards higher prescription rates and persisted to FU, independent of risk status and group allocation. Conclusions: The active implementation of a brief evidence-based educational intervention on global risk in CVD did not lead directly to risk-adjusted changes in prescription. Investigations on an extended time scale would capture whether decision support of this kind would improve prescribing risk-adjusted sustainably.
\end{abstract}

\title{
Keywords
}

Antihypertensive agents, aspirin, cardiovascular diseases, drug therapy, hydroxymethylglutaryl-CoA reductase inhibitors, primary health care

Received 2I July 2010; accepted I March 20II

\section{Introduction}

Guidelines suggest that prevention of cardiovascular disease (CVD) should start with global risk assessment and proceed to suitable treatment of correctable risk factors. ${ }^{1,2}$ Current guidelines recommend aspirin and lipid-lowering therapy for high-risk patients and evidence supports a similar approach for hypertension therapy. ${ }^{1-3}$ Treatment decisions based on single risk factors may more easily result in either over- or undertreatment. ${ }^{3}$ Various multivariate risk functions form the basis of predictive tools and risk scores., ${ }^{4,5}$ Evidence on the effectiveness of such tools on prescribing behaviour modification in prevention of CVD is still insufficient. ${ }^{6}$ General practitioners (GPs) are also
'Department of General Practice, University of Marburg, Germany.

${ }^{2}$ Clinical Ethics, University Hospital Zurich \& Institute of Biomedical Ethics, University of Zurich, Switzerland.

${ }^{3}$ Institute of General Practice, Family Medicine and Prevention, Paracelsus Medical University, Salzburg, Austria.

${ }^{4}$ Department of Family Medicine, University of Göttingen, Germany.

${ }^{5}$ AQUA-Institute for Applied Quality Improvement and Research in Health Care, Göttingen, Germany.

${ }^{6}$ Institute of Medical Biometry and Informatics, University of Heidelberg, Germany.

${ }^{7}$ Department of Medical Biometry and Epidemiology, University of Hamburg, Germany.

\section{Corresponding author:}

Heidemarie Keller, Department of General Practice, University of Marburg, Karl-von-Frisch-Strasse 4, 35032 Marburg, Germany

Email: kellerhe@staff.uni-marburg.de 
expected to involve their patients in decision-making. ${ }^{7,8}$ Up to date, neither individual CVD risk calculation. ${ }^{9-11}$ nor engagement of patients in their own healthcare decisions ${ }^{12}$ can be considered as being standard care. However, it still remains unclear which approach is best to implement evidence-based care into daily practice. $^{13,14}$

We developed Arriba, a simple evidence-based decision aid that combines risk calculation and consultation based on a patient's individual global risk for CVD. For the whole decision aid and materials, please refer to the supplemental appendix of Krones et al. ${ }^{15}$

In this article we present our results evaluating the impact on prescription. Changes in prescribing behaviour and appropriateness of prescription were analysed as secondary endpoints.

\section{Methods}

\section{Study population}

Hessian continuing medical education (CME) groups, coordinated by AQUA, a large German quality management institute, were screened for eligibility. CME groups were excluded if members routinely used cardiovascular risk calculators. Randomization to intervention or control group was done on CME-group level by the Centre for Clinical Trials, University of Marburg. GPs had to recruit up to 15 adult patients in who for any reason cholesterol levels were measured. To ensure that similar patients were included in both study arms, GPs were asked to approach all patients consecutively. Rolling recruitment of patients was spread evenly from May 2005 to March 2006.

The study complies with the Declaration of Helsinki. The research protocol was approved by the local research ethics committee, University of Marburg. Informed consent was obtained from all participating GPs and patients.

\section{Intervention}

Intervention GPs had to attend two CME sessions lasting 2.5 hours each. We discussed the epidemiological background of global cardiovascular risk calculation as well as ethics of shared decision-making by putting the emphasis on practical communication strategies and materials to be applied during consultation. Control GPs were invited to seminars on alternative topics that would not interfere with CVD prevention.

\section{Measures}

Arriba follows a baseline risk strategy by recommending a discussion with the patient about pharmacological interventions of hydroxymethylglutaryl-CoA reductase inhibitors (statins), inhibitors of platelet aggregation (IPA), or antihypertensive agents (AH) for anyone who has a risk of $15 \%$ or greater of developing CVD within the next 10 years, regardless of single risk factors. We investigated prescription of statins, IPA, and AH as well as any of these (total medication: statins or IPA or AH) as binary variables (yes or no). We compared the pre-study situation (BL), prescription at index consultation (IC), reflecting immediate effects of the intervention, and medication at 6-month follow-up (FU) reflecting long-term effects. Absolute cardiovascular risk was assessed according to the adapted Framingham equation, calibrated for European populations, ${ }^{16}$ based on the following risk factors [age, sex, total cholesterol, and high-density lipoprotein (HDL) cholesterol, systolic blood pressure with and without medication, smoking status] and was adjusted for diabetes. Baseline characteristics of GPs and patient data were obtained from study questionnaires. Prescription was considered appropriate in patients with high cardiovascular risk $(>15 \%)$ and no prescription in patients with low cardiovascular risk $(\leq 15 \%)$.

\section{Statistical analysis}

For binary/continuous outcome variables, we analysed differences between study groups by using mixed-effects logistic regression (procedure xtmelogit) in STATA (version SE 10.0) to allow for clustering by GP and CME-group (GP nested within CME group) with study arm as fixed effect. We added baseline characteristics at GP level (practice size as attendees per 3 months, years in practice, urban/rural, sex of GP) and at patient level (cardiovascular risk, diabetes, CVD (yes/no), subjective risk, age, sex, education) as covariates to the models. We further analysed prescription at IC and FU (total medication, IPA, statins, and $\mathrm{AH}$, respectively) as dependent variables and added study arm and premedication at BL as fixed effects. Pearson chi-squared test was used for the univariate comparison between study groups. Appropriateness of prescription was evaluated using binary variables (yes/ no) for each single medication. Results of two-sided tests between study arms were regarded significant at $p<0.05$. McNemar test was used to test for significant changes in prescribed medication over time within study groups, adjusted for multiple testing by Bonferroni correction $(\alpha=0.05 / 24=0.002)$. GPs failed to measure HDL cholesterol in 108 patients. We imputed missing values for HDL cholesterol, and single missing values for age, total cholesterol, and systolic blood pressure by using a maximum likelihood based algorithm (EM algorithm). 


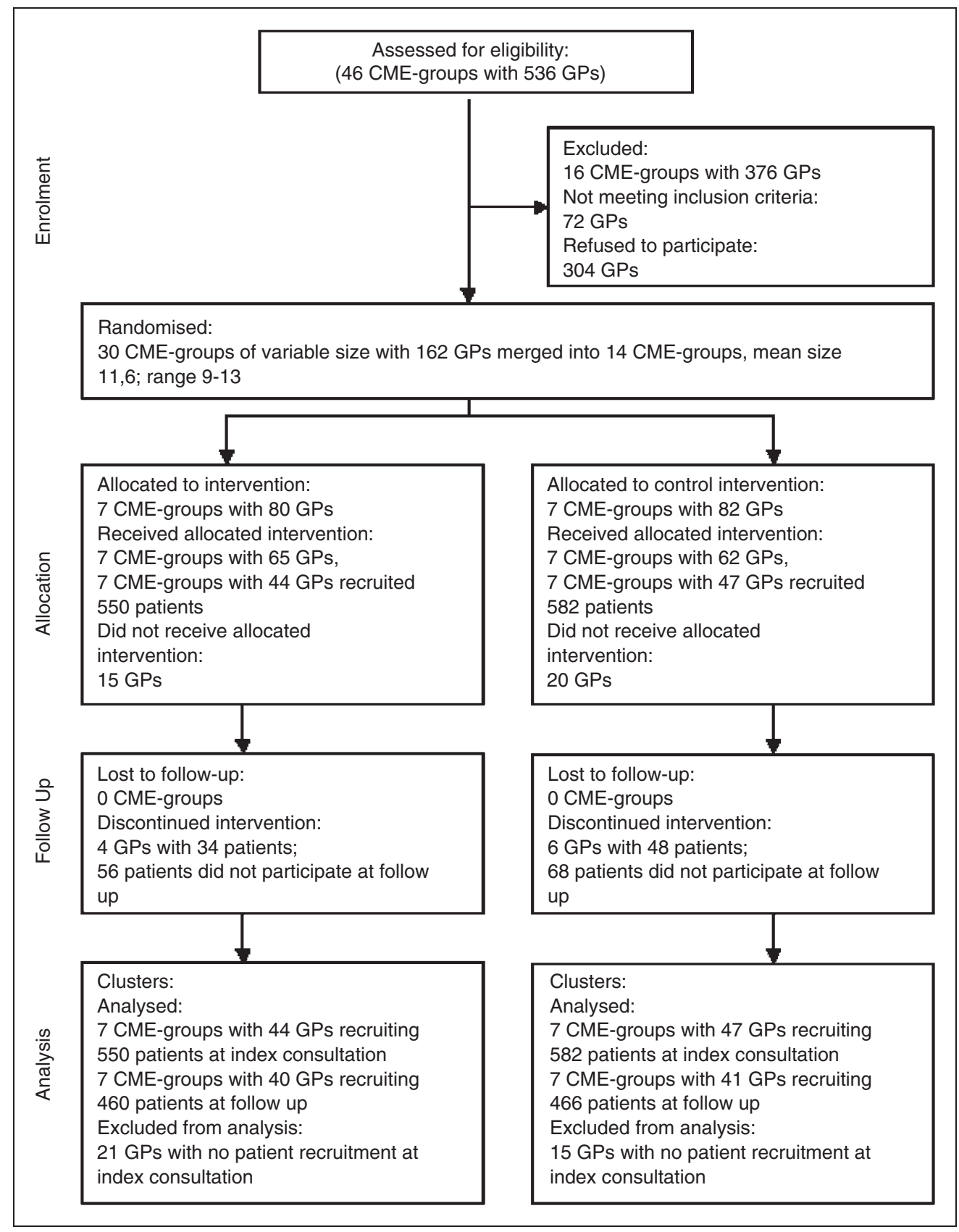

Figure I. Flow chart: continuous medical education (CME) groups, general practitioners (GPs), and patients.

For analyses at BL and IC we included all patients with valid data at IC. Estimates of prescribing at FU refer only to patients attending after 6 months.

Sample size was calculated using the original primary outcome measure, patient participation and satisfaction by the Patient Participation Scale. ${ }^{17}$ Results on main outcome measures have been published recently, including details on power calculations, recruitment rates, and baseline characteristics. ${ }^{15}$

Due to the explorative nature of this study, we avoided an additional arbitrary sample size calculation for this secondary outcome measure, aiming at the minimal clinically important difference as suggested by Man-Son-Hing et al. ${ }^{18}$

\section{Results}

\section{Study population}

Figure 1 gives an overview of the study population. Thirty CME groups consisting of 162 GPs were eligible and agreed to participate. Some small CME groups 
Table I. Baseline characteristics of participating general practitioners (GPs) by intervention and control group $(n=47)$

\begin{tabular}{lccc}
\hline Baseline variables & Intervention group $(n=44)$ & Control group $(n=47)$ & Chi-squared $p$-value \\
\hline GP age (years) & & & 0.57 \\
$\quad \leq 50$ & $26(59.1)$ & $25(53.2)$ & \\
$\quad>50$ & $18(40.9)$ & $22(46.8)$ & 0.56 \\
GP male & $27(61.4)$ & $26(55.3)$ & 0.78 \\
Geographical location (\% urban) & $20(45.5)$ & $20(42.6)$ & 0.003 \\
Attendees per 3-months (practice size) & & & \\
$\quad \leq 1000$ & $7(15.9)$ & $21(44.7)$ & $26(55.3)$ \\
$>1000$ & $37(84.1)$ & & 0.14 \\
Years in practice & $9(20.4)$ & $18(38.3)$ & \\
$0-10$ & $28(63.7)$ & $21(34.7)$ & \\
II-20 & $7(15.9)$ & $8(17.0)$ & \\
$21-30$ & & \\
\hline
\end{tabular}

Values are $n(\%)$, unless otherwise indicated. Data on age, practice size, and years in practice were primarily collected in categories.

were rearranged to make up a size of $9-13$ participants in each CME group, resulting in $14 \mathrm{CME}$ groups with 162 GPs. Of those, 127 practitioners attended the first of two educational sessions in either the intervention or the control arm. In the intervention arm, 44 GPs consecutively recruited 550 patients. In the control arm, 47 GPs similarly included 582 patients. At follow-up, 460 intervention patients $(83.6 \%)$ and 466 control patients $(80.1 \%)$ were seen. A total of 206 patients were lost to follow-up, 82 of which because their GP was no longer participating.

Baseline characteristics of participating GPs are shown in Table 1. With respect to patient characteristics (Table 2), study arms were well balanced for sociodemographic characteristics, prevalence of individual risk factors, and clinical disease as well as global risk, subjective risk, and subjective health. The number of patients with diabetes and CVD was significantly higher among control patients, which therefore were considered as covariates in the multivariate models. However, effect sizes according to $\operatorname{Cohen}^{19}$ and Grissom and $\mathrm{Kim}^{20}$ were low.

\section{Prescribing patterns and appropriateness of prescription}

Changes in prescription over time are displayed in Table 3. At BL, patients were treated similarly in both study groups, except for statins, where significantly more high-risk patients of the control group were under treatment $(p<0.001)$. Generally, in relation to $\mathrm{BL}$, changes in prescription over time were all directed towards higher prescription rates and persisted to FU, independent of risk status and group allocation. This resulted in an increased appropriateness of medical treatment in high-risk patients and in a decreased appropriateness in the low-risk patients in both groups. However, there still was an oversupply in the low-risk patients, whereas patients at high risk remained undersupplied. Compared to the control group, prescribing rates of IPA increased significantly $(p<0.001)$ in the intervention arm in both risk groups.

Significant predictors for changes in prescription over time (from BL to FU) could only be found for IPA and are listed in Table 4. In summary, at FU significantly more IPA was prescribed in intervention patients and in patients with lower education. Male GPs increased prescription of IPA up to FU significantly more often than female GPs. Prescription at FU was also highly influenced by premedication at BL. In contrast, no significant predictors were observed for statins and $\mathrm{AH}$.

In summary, it can be stated that we were able to show an intervention effect on prescribing for IPA only.

\section{Discussion}

Although we were able to show a slight intervention effect on prescribing for IPA, overall prescribing behaviour did not change when it was risk adjusted.

Our findings demonstrate a gap between recommended and current drug use for primary prevention of CVD, which is reflected by undersupply in the highrisk and the oversupply in the low-risk patients at follow-up.

The importance of a medication is context dependent and influenced by characteristics of the physician and/or patient. In our study, certain complaints of a patient might have been so salient for the physician that his or her attention had been directed towards a specific configuration of medication. 
Table 2. Baseline characteristics of patients by intervention and control group

\begin{tabular}{|c|c|c|c|}
\hline Variable & Intervention group $(n=550)$ & Control group $(n=582)$ & Chi-squared $p$-value \\
\hline Age (years, mean $\pm S D$ ) & $59.1 \pm 12.3$ & $58.6 \pm 12.5$ & 0.49 (t-test) \\
\hline Sex (male) & $231(42.0)$ & $265(45.5)$ & 0.26 \\
\hline Nationality (German) & $528(96.0)$ & $566(97.3)$ & 0.46 \\
\hline Education & & & $0.7 \mathrm{I}$ \\
\hline No or basic education & $284(5 \mathrm{I} .6)$ & $320(54.9)$ & \\
\hline Medium education & $169(30.7)$ & $168(28.9)$ & \\
\hline Higher education & $91(16.6)$ & $91(15.6)$ & \\
\hline Positive family history of CVD & $51(9.3)$ & $45(7.8)$ & 0.362 \\
\hline Smokers & $102(18.5)$ & $108(18.6)$ & 1.0 \\
\hline Diabetes & $74(13.5)$ & $160(27.5)$ & $<0.00 I^{c}$ \\
\hline Known cardiovascular disease (CVD) & $26(4.7)$ & $6 \mathrm{I}(10.5)$ & $<0.00 \mathrm{I}^{\mathrm{c}}$ \\
\hline Subjective risk status & & & 0.021 \\
\hline Low-very low & 357 (64.9) & $327(56.2)$ & \\
\hline High-very high & $95(17.3)$ & $108(18.5)$ & \\
\hline Don't know & $98(17.8)$ & $147(25.3)$ & \\
\hline Subjective health status & & & 0.27 \\
\hline Good-very good & $266(48.9)$ & $260(45.0)$ & \\
\hline Satisfactory & $242(44.5)$ & $278(48.1)$ & \\
\hline Bad-very bad & $36(6.7)$ & $40(6.9)$ & \\
\hline \multicolumn{4}{|l|}{ Cardiovascular risk status $^{\mathrm{a}}$} \\
\hline$\leq 15 \%$ & $289(54.9)$ & $308(54.4)$ & 0.86 \\
\hline$>15 \%$ & $237(45.1)$ & $258(45.6)$ & \\
\hline Manifest atherosclerosis ${ }^{b}$ & $110(21.0)$ & $139(28.0)$ & 0.12 \\
\hline Risk factors (mean $\pm S D$ ) & & & $t$-test $p$-value \\
\hline Triglycerides (mmol/l) & $\mathrm{I} .8 \pm \mathrm{I} .2$ & $\mathrm{I} .8 \pm \mathrm{I} . \mathrm{I}$ & 0.74 \\
\hline Total cholesterol (mmol/l) & $6.0 \pm 1.2$ & $5.7 \pm I . I$ & $<0.00 \mathrm{I}, d=0.26^{\mathrm{d}}$ \\
\hline HDL-cholesterol (mmol/l) Syst. & $1.6 \pm 0.4$ & $1.5 \pm 0.5$ & 0.15 \\
\hline Blood pressure (mmHG) & $132 \pm 17.3$ & $132 \pm 17.4$ & 0.92 \\
\hline $\mathrm{Hb}_{\mathrm{Alc}}(\%)$ & $6.2 \pm 1.1$ & $6.7 \pm 1.2$ & $<0.00 \mathrm{I}, d=0.44^{\mathrm{d}}$ \\
\hline Blood glucose $(\mathrm{mmol} / \mathrm{l})$ & $5.3 \pm 1.7$ & $5.7 \pm 1.9$ & $<0.001, d=0.22^{d}$ \\
\hline
\end{tabular}

Values are $n(\%)$, unless otherwise indicated. ${ }^{a}$ Cardiovascular risk calculation based on Framingham equation (see methods section). ${ }^{b}$ Manifest atherosclerosis defined according to the International Statistical Classification of Diseases and Related Health Problems (ICD) edited by the WHO (ICD-10, revised version 2006). 'Effect size calculated from contingency table: diabetes: Cohen's $w=-0.173$ (95\% Cl -0.23 to -0.12 ); CVD: Cohen's $w=-0.1 I(95 \% \mathrm{Cl}-0.16$ to -0.05$)$. 'Effect size calculated as the difference between two means divided by a SD as Cohen's $d .{ }^{19}$

Among others, a high-risk patient not on medication might have had side effects in the past, had discontinued medication on his own, had refused to take medication, or preferred to try behavioural changes first, after having discussed the therapeutic options for evidence-based risk reduction, given the potential mixed effects of our decision aid, even if professionals had changed their behaviour. On the other side, a low-risk patient's risk might have been lowered because of treatment and thus prescribed medication might have been appropriate. Apart from that, as patient age increases, age might have been taken into account when reconsidering prescription.
Our findings correspond to studies, which covered treatment recommendations that are inconsistent with contemporary guidelines. ${ }^{21,22}$ Persell et al. ${ }^{23}$ reported that providing 10-year coronary risk information improved aspirin-prescribing decisions and lipid management when the short-term risk was moderately high. However, important treatment gaps remained and guidelines still were not followed for eligible patients. This is supported by Vlek et al. ${ }^{24}$ who evaluated trends in vascular risk factors and medication use in cardiovascular diseases over a 12-year period. In contrast, Hall et al. ${ }^{25}$ found an increase in prescription of preventive medications to 
Table 3. Changes in prescribed medication over time, from prior to study start to index consultation and follow up

\begin{tabular}{|c|c|c|c|c|}
\hline \multirow[b]{2}{*}{ Medication } & \multicolumn{2}{|c|}{ Intervention group } & \multicolumn{2}{|l|}{ Control group } \\
\hline & $\begin{array}{l}\text { Patients under } \\
\text { treatment (\%) }\end{array}$ & $\begin{array}{l}\text { McNemar } \\
\text { ( } p \text {-value) }\end{array}$ & $\begin{array}{l}\text { Patients under } \\
\text { treatment (\%) }\end{array}$ & $\begin{array}{l}\text { McNemar } \\
\text { ( } p \text {-value) }\end{array}$ \\
\hline \multicolumn{5}{|c|}{ Low risk status $(\leq 15 \%)$} \\
\hline \multicolumn{5}{|c|}{ Total medication } \\
\hline BL-IC & $34.3-49.2$ & $<0.001$ & $36.5-47.8$ & $<0.001$ \\
\hline BL-FU & $34.3-47.7$ & $<0.001$ & $36.5-44.9$ & $<0.001$ \\
\hline \multicolumn{5}{|c|}{ Statins (hydroxymethylglutaryl-CoA reductase inhibitors) } \\
\hline BL-IC & $5.5-8.7$ & 0.022 & $8.8-11.7$ & 0.049 \\
\hline BL-FU & $5.5-7.5$ & 0.754 & $8.8-11.9$ & 0.115 \\
\hline \multicolumn{5}{|c|}{ Inhibitors of platelet aggregation } \\
\hline BL-IC & $7.3-14.9$ & $<0.001$ & $6.5-6.8$ & 1.0 \\
\hline BL-FU & $7.3-14.2$ & $<0.001$ & $6.5-7.8$ & 0.250 \\
\hline \multicolumn{5}{|c|}{ Antihypertensive agents } \\
\hline BL-IC & $29.8-34.8$ & $<0.001$ & $32.5-36.2$ & 0.001 \\
\hline BL-FU & $29.8-38.7$ & $<0.001$ & $32.5-38.3$ & 0.001 \\
\hline \multicolumn{5}{|c|}{ High risk status (>15\%) } \\
\hline \multicolumn{5}{|c|}{ Total medication } \\
\hline BL-IC & $73.1-86.9$ & $<0.001$ & $76.2-84.9$ & 0.022 \\
\hline BL-FU & $73.1-85.2$ & $<0.001$ & $76.2-83.7$ & 0.022 \\
\hline \multicolumn{5}{|c|}{ Statins (hydroxymethylglutaryl-CoA reductase inhibitors) } \\
\hline BL-IC & $26.1-30.5$ & 0.043 & $36.7-39.8$ & 0.047 \\
\hline BL-FU & $26.1-29.1$ & 0.115 & $36.7-43.4$ & 0.031 \\
\hline \multicolumn{5}{|c|}{ Inhibitors of platelet aggregation } \\
\hline BL-IC & $25.1-46.4$ & $<0.001$ & $27.3-27.7$ & 1.0 \\
\hline BL-FU & $25.1-46.2$ & $<0.001$ & $27.3-29.3$ & 1.0 \\
\hline \multicolumn{5}{|c|}{ Antihypertensive agents } \\
\hline BL-IC & $63.4-69.1$ & $<0.001$ & $68.8-75.7$ & $<0.001$ \\
\hline BL-FU & $63.4-73.3$ & 0.001 & $68.8-79.2$ & $<0.001$ \\
\hline
\end{tabular}

$p$-values adjusted for multiple testing by Bonferroni correction $(\alpha=0.05 / 24=0.002), p<0.002$. BL, prior to study start; IC, index consultation; FU, follow up.

Table 4. Significant predictors for changes in prescription of inhibitors of platelet aggregation over time: mixed effects logistic regression

\begin{tabular}{lccc}
\hline Variable & z-values & $p$-value & Odds ratio $(95 \% \mathrm{Cl})$ \\
\hline Study arm & -4.69 & $<0.00 \mathrm{I}$ & $0.056(0.02-0.19)$ \\
Premedication of IPA at BL & 9.12 & $<0.00 \mathrm{I}$ & $4685.52(762.36-28797.39)$ \\
Patient education & -2.35 & 0.019 & $0.56(0.34-0.91)$ \\
GP sex & -2.02 & 0.044 & $0.49(0.25-0.98)$ \\
\hline
\end{tabular}

$\mathrm{BL}$, prior to study start; $\mathrm{Cl}$, confidence interval; GP, general practitioner; IPA, inhibitors of platelet aggregation.

high-risk individuals without a change in the lowrisk group. Similarly, Grover et al. ${ }^{26}$ indicated that discussing coronary risk with the patient was associated with an improvement in the efficacy of lipid therapy.
One contributing factor for inadequate prescription in our study could have been that a patient's risk of CVD was not accurately estimated. This corresponds to van Dis et al. ${ }^{27}$ who stated that overestimation of CVD mortality risk may result in pharmacological 
overtreatment. Sheridan and Crespo ${ }^{3}$ concluded that physicians' knowledge of global CHD risk scores may translate into modestly increased prescribing of cardiovascular drugs.

Most common barriers to guideline implementation, as reported by Graham et al., ${ }^{28}$ are patient compliance, a lack in time, and government health policy. In contrast, financial opportunities and simple guidelines are suggested to improve the implementation.

Implementation requires clear and deliverable evidence-based messages, evidence that current care is suboptimal, a robust estimate of the cost, impact of alternative methods of behavioural change, and an understanding of the local organization of health care. $^{13,29}$

\section{Strengths and limitations}

Arriba was not conducted as pharmacological intervention study. Therefore, results have to be interpreted with caution. Although we did adjust for multiple testing, our analysis here is based on secondary outcome criteria.

Methodological aspects such as cross-quarterly supply or prescription by specialists could not have been recorded here. That is why 'appropriateness of prescription' as defined in our study should be seen as a measure to compare study arms, but well known that it does not necessarily reflect widespread reality of prescribing behaviour.

GPs in the control arm recruited more diabetic and more high-risk patients, which may reflect a selection bias at patient level.

Furthermore, recruitment of CME groups might implicate a selection bias at physician level, which might result in an overestimation of intervention effects.

Based on our exclusion criterion, not having used any risk calculator ahead of the study, our sample might just as well reflect late adopters, which may then lead to an underestimation of intervention effects.

Since control GPs were treated similarly compared to the intervention GPs and given other constraints regarding prescription (GPs are held accountable for their prescribing costs individually), we regard a Hawthorne effect in the control arm as unlikely.

Given the pragmatic study design, concealment of patient allocation and blinding of GPs were not possible.

\section{Conclusions}

Crucial research findings often do not translate automatically into practice. Our results suggest that a brief active implementation of an evidence-based educational intervention does not lead immediately to changes in prescription. This may be the case because physicians are embedded in an organizational framework which prevents them from changing prescription rapidly. Only investigations on an extended time scale would capture, whether decision support of this kind would improve prescribing risk-adjusted sustainably.

\section{Acknowledgements}

We acknowledge with thanks the assistance of our study coordinators Beate Czypionka, Ute Dietrich, and Ursula Siegmund. We would also like to thank all participating GPs and patients. Grateful thanks also to Cornelia Kirst from the AQUA Institute for contacting CME-groups. Portions of the manuscript's contents have been presented at WONCA Conference, Florence, Italy, August 2006, ISDM conference, Freiburg, Germany, September 2007, DEGAM conference, September 2006, Berlin, Germany, and ISDM conference, Boston, USA, June 2009.

\section{Funding}

This work was supported by the German Federal Ministry of Education and Research (grant number 01GK0401).

\section{Clinical trial registration}

This trial is registered at www.controlled-trials.com (number ISRCT71348772).

\section{Conflict of interest}

None.

\section{References}

1. De Backer G, Ambrosioni E, Borch-Johnsen K, Brotons C, Cifkova R, Dallongeville J, et al. European guidelines on cardiovascular disease prevention in clinical practice. Eur Heart J 2003; 24(17): 1601-1610.

2. Graham I, Atar D, Borch-Johnsen K, Boysen G, Burell G, Cifkova R, et al. European guidelines on cardiovascular disease prevention in clinical practice. Eur J Cardiovasc Prev Rehabil 2007; 14(Suppl 2): 1-113.

3. Sheridan SL and Crespo E. Does the routine use of global coronary heart disease risk scores translate into clinical benefits or harms? A systematic review of the literature. BMC Health Serv Res 2008; 8: 60.

4. Cooney MT, Dudina AL and Graham IM. Value and limitations of existing scores for the assessment of cardiovascular risk: a review for clinicians. $J$ Am Coll Cardiol 2009; 54(14): 1209-1227.

5. D'Agostino Sr RB, Vasan RS, Pencina MJ, Wolf PA, Cobain M, Massaro JM, et al. General cardiovascular risk profile for use in primary care: the Framingham Heart Study. Circulation 2008; 117(6): 743-753.

6. Steenkiste van B, Weijden van der T, Stoffers HEJH, Kester ADM, Timmermans DRM and Grol R. Improving cardiovascular risk management: a randomized, controlled trial on the effect of a decision support tool for patients and physicians. Eur J Cardiovasc Prev Rehabil 2007; 14(1): 44-50. 
7. O'Connor AM, Bennett CL, Stacey D, Barry M, Col NF, Eden KB, et al. Decision aids for people facing health treatment or screening decisions. Cochrane Database Syst Rev 2009; 3: CD001431.

8. Edwards A and Elwyn G (eds) Shared decision-making in health care: Achieving evidence-based patient choice, 2nd ed. Don Mills, Ontario: Oxford University Press, 2009.

9. Cooney MT, Dudina A, D’Agostino R and Graham IM. Cardiovascular risk-estimation systems in primary prevention: do they differ? do they make a difference? can we see the future? Circulation 2010; 122(3): 300-310.

10. Goldman RE, Parker DR, Eaton CB, Borkan JM, Gramling R, Covert RT and Ahern DK. Patients' perceptions of cholesterol, cardiovascular disease risk, and risk communication strategies. Ann Fam Med 2006; 4(3): 205-212.

11. Sheridan SL, Viera AJ, Krantz MJ, Ice CL, Steinman LE, Peters KE, et al. The effect of giving global coronary risk information to adults: a systematic review. Arch Intern Med 2010; 170(3): 230-239.

12. Coulter A and Ellins J. Effectiveness of strategies for informing, educating, and involving patients. BMJ 2007; 335(7609): 24-27.

13. Wensing M, Broge B, Kaufmann-Kolle P, Andres E and Szecsenyi J. Quality circles to improve prescribing patterns in primary medical care: what is their actual impact? J Eval Clin Pract 2004; 10(3): 457-466.

14. Grimshaw JM, Thomas RE, MacLennan G, Fraser C, Ramsay CR, Vale L, et al. Effectiveness and efficiency of guideline dissemination and implementation strategies. Health Technol Assess 2004; 8(6): iii-iv, 1-72.

15. Krones T, Keller H, Sönnichsen A, Sadowski EM, Baum E, Wegscheider K, et al. Absolute cardiovascular disease risk and shared decision making in primary care: a randomized controlled trial. Ann Fam Med 2008; 6(3): 218-227.

16. Sullivan LM, Massaro JM and D'Agostino RB. Presentation of multivariate data for clinical use: the Framingham Study risk score functions. Stat Med 2004; 23(10): 1631-1660.

17. Man Son Hing M, Laupacis A, O’Connor AM, Biggs J, Drake E, Yetisir E, et al. A patient decision aid regarding antithrombotic therapy for stroke prevention in atrial fibrillation. JAMA 1999; 282(8): 737-743.

18. Man-Son-Hing M, Laupacis A, O'Rourke K, Molnar FJ, Mahon J, Chan KBY, et al. Determination of the clinical importance of study results: a review. J Gen Intern Med 2002; 17(6): 469-476.

19. Cohen J. Statistical power analysis for the behavioral sciences. Hillsdale: Lawrence Erlbaum Associates, 1988.

20. Grissom RJ and Kim JJ. Effect sizes for research: A broad practical approach. Mahwah: Lawrence Erlbaum Associates, 2005.

21. Mosca L, Linfante AH, Benjamin EJ, Berra K, Hayes SN, Walsh BW, et al. National study of physician awareness and adherence to cardiovascular disease prevention guidelines. Circulation 2005; 111(4): 499-510.

22. Smith MA, Cox ED and Bartell JM. Overprescribing of lipid lowering agents. Qual Saf Health Care 2006; 15(4): 251-257.

23. Persell SD, Zei C, Kenzie A, Cameron KA, Zielinski M, Donald M, et al. Potential use of 10-year and lifetime coronary risk information for preventive cardiology prescribing decisions: a primary care physician survey. Arch Intern Med 2010; 170(5): 470-477.

24. Vlek A, Visseren F, Algra A, Soedamah-Muthu S, Moll F, Doevendans $P$, et al. Trends in vascular risk factors and medication use in patients with various manifestations of vascular diseases or type 2 diabetes mellitus from 1996 to 2007: the Second Manifestations of ARTerial disease study. Eur J Cardiovasc Prev Rehabil 2010; 17(6): 628-636.

25. Hall LM, Jung RT and Leese GP. Controlled trial of effect of documented cardiovascular risk scores on prescribing. BMJ 2003; 326(7383): 251-252.

26. Grover SA, Lowensteyn I, Joseph L, Kaouache M, Marchand S, Coupal L, et al. Patient knowledge of coronary risk profile improves the effectiveness of dyslipidemia therapy. Arch Intern Med 2007; 167(21): 2296-2303.

27. van Dis I, Kromhout D, Geleijnse JM, Boer JMA and Verschuren WMM. Evaluation of cardiovascular risk predicted by different SCORE equations: The Netherlands as an example. Eur $J$ Cardiovasc Prev Rehabil 2010; 17(2): 244-249.

28. Graham IM, Stewart M and Hertog MG. Factors impeding the implementation of cardiovascular prevention guidelines: findings from a survey conducted by the European Society of Cardiology. Eur J Cardiovasc Prev Rehabil 2006; 13(5): 839-845.

29. Grol R and Grimshaw J. From best evidence to best practice: effective implementation of change in patients' care. Lancet. 2003; 362(9391): 1225-1230. 